\section{Palofra}

acceso $\odot$ abierto

Cómo citar: Roa, W. (2020). Más que una representación del indígena en el filme Jericó (1990). Palobra, 20(1), 4-22. https://doi.org/10.32997/2346-2884-vol.20num.1-2020-3221

Recibido: 13 de enero de 2020

Aprobado: 15 de abril de 2020

Editora: Rosario Blanco Bello. Universidad de Cartagena-Colombia.

Tipología IBN Publindex: Artículo de Reflexión.

\title{
Más que una representación del indígena en el filme Jericó (1990)
}

\author{
More than an india role play on the film Jericó (1990)
}

William Alfonso Roa-Barraza

Asociación Centro de Historia de Sabanalarga, Atlantico-Colombia,wiroba2009@hotmail.com

\section{RESUMEN}

El cine y la disciplina de la historia presentan acercamientos importantes en los últimos años, a pesar del recelo de investigadores tradicionales. Por esta razón presentamos como propuesta el análisis de la película Jericó ya que los medios de comunicación ejercen gran influencia sobre los imaginarios colectivos. Para ello hicimos un rastreo de los filmes producidos en la coyuntura de la Celebración del Quinto Centenario de América para luego exponer los inconvenientes presentados en este tipo de fuentes audiovisuales. Asimismo, mostramos los discursos ideológicos de políticos, academicistas y de películas venezolanas que abordaron las comunidades nativas para develar que Luis Alberto Lamata rompió con un paradigma cinematográfico en su país debido a que representó a los indígenas como seres humanos.

Palabras clave: historia; cine histórico; Jericó; representación del indígena; interpretación historiográfica; Venezuela.

\begin{abstract}
The movie and the discipline of history have been important approachings in recent years, despite the suspicion of traditional researchers. For this reason, we presented as a proposal the analysis of the film Jericho since the media exerts great influence on collective imaginaries. To do this we traced the films produced at the juncture of the Celebration of the Fifth Centenary of America and then exposed the inconveniences presented in this type of audiovisual sources. We also show the ideological discourses of Venezuelan politicians, academics and films that were addressed by native communities to reveal that Luis Alberto Lamata broke with a cinematic paradigm in his country because he represented indigenous people as human beings.
\end{abstract}

Keywords: history; historical cinema; Jericó; representation of the indigenous; historiographic interpretation; Venezuela. 


\section{INTRODUCCIÓN}

Durante la coyuntura del descubrimiento de América el cine se incorporó a esta celebración con los largometrajes: El Dorado de Carlos Saura (1988), Cabeza de Vaca de Nicolás Echevarría (1990), Jericó de Luis Alberto Lamata (1990), El Manto Negro de Bruce Beresford (1991), 1492. La conquista del paraíso de Ridley Scott (1992), Cristóbal Colón. El descubrimiento de John Glen (1992), La otra conquista de Salvador Carrasco (1998) y Hacia la ruta del Dorado de Eric Bergeron, Don Paul, Will Finn y David Silverman (2000). En tal sentido estudiaremos la representación del indígena a través del discurso visual del cine histórico de ficción Jericó. La escogencia de esta película no fue al azar sino una elección basaba en el criterio de que el cineasta tiene formación en el campo de la historia. Para este propósito tuvimos en cuenta dos componentes que nos permitieron conocer la relevancia de la cinta analizada debido a que esta rechazó las visiones y estereotipos de filmes venezolanos planteando así una nueva reinterpretación y construcción de la imagen del indio. El primero la posición de intelectuales sobre el aborigen. El segundo los largometrajes de los 80 sobre el nativo. Intentaremos dar respuesta a estos interrogantes principales, pero no únicos: ¿Cómo simbolizó Lamata al indígena para rechazar los arquetipos anteriores a su película? ¿Qué posturas impulsaron intelectuales sobre los grupos étnicos? ¿En qué se apoyaron? ¿Cuáles son los filmes venezolanos del decenio de los 80 ?

\section{Cine histórico de ficción: desafíos para su estudio}

La disciplina de la historia cumple un papel importante para el conocimiento debido a que ella estudia las actividades humanas en el tiempo y en el espacio. Su objetivo principal es explicar la dinámica de la sociedad en sus estructuras; analizadas a través de la heurística, las fuentes orales, visuales y documentales. Y, con la interpretación hermenéutica, llegar al discernimiento de lo sucedido en el pasado, para su explicación y síntesis histórica. Como expresó Cicerón, "la historia es la ciencia de los hombres en el tiempo, el análisis de las sociedades humanas sujetas a cambios y en continua transformación" (Ocampo, 2009, p. 204).

La historiográfica tradicional es logocéntrica debido a que concibe la historia como una disciplina que explica eventos recibidos del pasado. Esta afirmación continúa predominando hasta el punto de que las imágenes solo se perciben como complemento para la construcción de un texto. No hay necesidad de rechazar el valor de la palabra como lenguaje cotidiano de los seres humanos y herramienta de exteriorización del pensamiento. Pero también hay que reivindicar las imágenes, el lenguaje audiovisual del cine y la televisión debido a que permiten acoplar palabras, voces, entonaciones, dicciones, iconografías del pasado y del presente (Sánchez, 2008). 
Cuando analizamos largometrajes debemos dejar de esperar que acierten con los hechos; exhiban las diferentes caras de un problema; o que traten de manera imparcial las pruebas, personajes y grupos que aparecen en una situación determinada; contextualicen de forma histórica y describan un acontecimiento. En otras palabras, las <<películas históricas de ficción〉> no son precisas debido a que una de las peculiaridades principales y objetivos de los filmes es generar movimiento, color, sonido y drama al pasado. Por su parte, las obras de la «historia escrita» tampoco son espejos de lo real sino construcciones, trabajos cuyas metodologías para relacionarse con las huellas del pasado y representarlo son necesariamente diferentes (Rosentstone, 2008).

Una simple definición de filme histórico es la siguiente: aquella que sitúa su acción en un pasado reconocible con respecto a la actualidad de su producción. Esta identificación pasará por la acumulación de detalles e indicios capaces de otorgar veracidad al discurso audiovisual y de hacerlo trabajar a favor de un cierto sentido histórico. De tal manera que el cine se mueve entre la descripción del pasado y su interpretación. De acuerdo con la propuesta se queda en una simple visualización o una reinterpretación del mismo (Acosta y Suerio, 2000).

El cineasta crea un pasado acorde con las exigencias, prácticas y tradiciones de los medios audiovisuales. Esta tarea lo obliga a enfrentarse a la invención de hechos, gestos y entonaciones. Esto no significa que películas hayan sido reconocidas por sus contribuciones al conocimiento histórico y cineastas sean considerados como historiadores. El reconocimiento de estos largometrajes y directores se manifiesta en los trabajos impresos de estudiosos (Rosentstone, 2008).

Es conveniente advertir que el cine histórico no podrá suplir la historia escrita, es decir, la cinematografía por sí solo no es capaz de enseñar. Una película construye la historia como una narración cerrada, con su nudo, desarrollo y desenlace; se caracteriza por una fuerte carga dramática, llena de emociones, miedos, aventuras y heroísmo. Individualiza los procesos a través de las experiencias de sus protagonistas, de cuyas pasiones y sentimientos depende el suceder de los acontecimientos, elevándose al rango de leyes generales que rigen la historia (Martínez, 2013). La condición de espectáculo del cine implica que la historia quede de telón de fondo (tramas aventureras, melodramáticas, terroríficas, cómicas, etc.) de un relato subordinado a unas leyes narrativas y del espectáculo, distinta a la historia como tal. Modelos de la tradición escénica han llevado a que se priorice lo intensivo sobre lo extensivo; lo dramático de lo narrativo. Los filmes históricos se caracterizan por el predominio de una dualidad héroe/villano, amigo/traidor, mujer abnegada/ mujer fatal, entre otros (Acosta y Suerio, 2000). 
Su sentido histórico lo ha resumido la publicidad con la frase cliché: "basada en una historia real”, pero las representaciones e intenciones de la película no se limitan al guion ya que la promoción de la misma orienta al espectador (Montero, 2008).

Esto no implica negar la validez al cine histórico. Este tipo de cinematografía sirve para la divulgación de hechos del pasado y una pertinente y educativa reflexión sobre valores morales y cívicos (Sánchez, 2008). La imagen audiovisual como fuente histórica requiere de nuevas herramientas propias de las fuentes de representación visual que permitan su interpretación. Hace unas décadas Pierre Vilar escribió: "la historia debe enseñarnos, en primer lugar, a leer un periódico" hay que agregar a esta definición que debería enseñar también a ver y escuchar un telediario y una película (Martínez, 2013, p. 354).

\section{De los creadores del films: Jericó (1990)}

El director del film Luis Alberto Lamata, nació en la ciudad de Caracas, Venezuela, en 1959. En este país cursó una Licenciatura en Historia, en la Universidad Central. Asimismo, participó en la creación de varias telenovelas como, por ejemplo, Cristal (1985-1986), La traidora (1991-1992), y como director de la telenovela Topacio (1985), esta última de gran recepción en el ámbito internacional. Del mismo modo, filmó cortometrajes para cine, hasta que en 1990 hizo el largometraje Jericó, película que puede ser clasificada como de cine histórico de ficción, esta fue estrenada en el V Festival de Cine Nacional de Mérida, bajo el segundo gobierno de Carlos Andrés Pérez, entre 1989 y 1993.

Jericó es una producción de Thalía Producciones y Foncine, con apoyo de Bolívar Films y la Fundación Cinemateca Nacional. Tiene un tiempo estimado de 90 minutos y se enmarca dentro del período de la conquista de América, para ser más precisos, durante las primeras décadas del siglo XV en Tierra Firme. Merece especial atención, que el discurso es lineal, no hay regresiones; utiliza el recurso de la voz en off el cual actúa como conciencia. Los diálogos de los personajes son cortos y por tanto el cineasta se apoyó principalmente en la iconografía.

El largometraje buscó impulsar una nueva representación fílmica del indígena como ser humano y no como un salvaje que había que civilizar, para así advertir que estos grupos étnicos tienen distinta interpretación de las realidades que los rodean. Esta producción obtuvo reconocimientos y premios internacionales: Ópera Prima en Biarritz, en Francia, el Premio Coral como mejor largometraje en La Habana, Cuba, el Premio Especial del Jurado en la ciudad de Cartagena, Colombia, y ganó el Premio Especial de Jurado en el Festival de Trieste en Italia. Sus logros no acaban aquí, pues en el Primer Congreso de Cultura Iberoamericana, realizado en México, en 2008, fue seleccionada entre las 50 producciones iberoamericanas más importantes. 
La película, como las representaciones, es una reducción y una interpretación. $\mathrm{Su}$ producción depende de la personalidad de quien la realizó, de su conocimiento en el tema, del receptor a quien va dirigida. Estas condiciones son expresadas en los textos, documentos, entrevistas, imágenes, pero se hacen más notorias y visibles en los filmes (Sorlin, 2008). Debido a su formación de historiador y cineasta, a la coyuntura de la celebración del encuentro de dos mundos o desencuentro y resistencia del descubrimiento de América, la película está influenciada por la corriente historiográfica llamada "nueva historia".

De acuerdo con el investigador e historiador Enrique Ayala (1992):

La Nueva Historia ha surgido, pues, en un contexto social específico y su producción debe juzgarse dentro de ese marco. Aunque no se puede hallar ni una orientación teórico-metodológica específica, ni una temática especialmente tratada, son fácilmente rastreables al menos dos bases comunes de trabajo. Se parte, en primer lugar, de la aceptación de que los protagonistas de la historia no son los individuos, sino los grupos (clase, etnias, sociedades). Se acepta, en segundo lugar, que el análisis de los fenómenos históricos parta de la consideración de la estructura económico-social. En este sentido, debe inscribirse el movimiento general en actitudes teórico-políticas, que van desde varias posiciones de izquierda hasta el reformismo. Luego de un primer momento en que especialistas de otras disciplinas hicieron historia, ha ido apareciendo una nueva generación de historiadores profesionales que han consolidado ya la Nueva Historia como actividad científica (p. 104).

La nueva corriente historiográfica tiene como principal característica su eclecticismo. Su propósito consiste en superar las limitaciones de la historiografía "positivista" con su apego al hecho singular; una mecánica narración de efemérides cotidianas y un conjunto de generalidades abstractas a través de la utilización de unas amplias herramientas metodológicas modernas. A continuación, mencionamos autores suramericanos de esta corriente contemporánea: Tulio Halperin, Enrique Flores Cano, Arnaldo Córdova, Germán Carrera Damas, Arístides Medina Rubio, Germán Colmenares, Álvaro Tirado Mejía, Pablo Macera, Luis Guillermo Lumbreras y Alejandro Witker. Estos abordan el análisis histórico con métodos científicos mediante el acompañamiento de las demás ciencias sociales: Antropología, sociología, geografía, economía, con una actitud crítica y hasta puede considerarse, revalorizadora, ya que pretende interpretar los hechos históricos en su integralidad, es decir, teniendo en cuenta las actividades de los grupos humanos, la mentalidad colectiva e individual, las situaciones coyunturales, la historia regional para de esta manera superar la simple descripción de acontecimientos (Guerra, 2003). 


\section{La representación del indio en el films Jericó en la coyuntura del descubrimiento de América}

En esta parte debemos destacar y recordar las palabras del investigador, Peter Burker (2005):

El poder de una película consiste en que da al espectador la sensación de que está siendo testigo ocular de los acontecimientos. Pero ése es también el peligro que conlleva este medio --como le ocurre a la instantánea-, pues dicha sensación es ilusoria. El director manipula la experiencia permaneciendo invisible. Y al director le interesa no sólo lo que sucedió realmente, sino también contar una historia que tenga una determinada estructura artística y atraiga al mayor número posible de espectadores. (...) El argumento fundamental es que una historia filmada, lo mismo que una historia pintada o escrita, constituye un acto de interpretación (p. 202).

La cinta gira en torno a un fraile dominico llamado Santiago, quien partió desde España en una expedición alemana que respondía a los intereses de la factoría de los Welser. El religioso llegó a estos espacios (parte del actual territorio de Venezuela), con el propósito de convertir a los indios Caribes en cristianos para salvarles el alma del pecado y transformarlos en verdaderos hijos de Dios. Su preocupación quedó expuesta en la frase "Allá fuera viven hombres y mujeres que no tienen derecho al cielo” (Lamata, 1990).

Estas convicciones religiosas pronto se debilitaron ante las realidades de un nuevo mundo, evidenciado en las comunidades indígenas con su lengua, comportamiento y costumbres que se alejaban de los preceptos bíblicos que el fraile manejaba por formación teológica. Es decir, que sus códigos y valores morales no se ajustaban a las circunstancias que lo rodeaban.

En medio de esta disputa interna, Santiago se familiarizó con ese mundo desconocido, despojándose cada día de esa doctrina que lo tenía anclado en un pasado que solo vivía en su mente y le impedía disfrutar de compartir en sociedad, de sentir los placeres del amor y formar una familia con una mujer que vino a conquistar espiritualmente. En últimas el salvado fue él debido a que logró comprender y adaptarse al entorno al que ahora pertenecía.

Si eres Dios deberías empezar por ser hombre, así sabrías lo que es cargar en tus huesos el dolor de la vida. Sabrías del pan y la carne, sabrías también que no hay frontera cierta que no separe el mal del bien, y tal vez algún día pensarás como yo lo hago ahora, que toda la verdad del mundo (...) está sobre la piel de una mujer y la sonrisa fugaz de un niño. (...) El paraíso solo existe en mi cabeza y en la oscuridad de mi encierro me queda la ilusión de un mundo diferente (Lamata, 1990).

Para comprender la representación que Lamata (1990) planteó del nativo en Jericó es preciso analizar la interpretación historiográfica que podía ser 
considerada como tradicional, y desde luego, la mirada de políticos, academicistas y del cine venezolano en la década de los 80 en torno a las comunidades nativas. En cuanto a la historiografía tradicional, mucha de ella se apoyó en los cronistas con su interpretación eurocéntrica, asumiendo incluso estas posiciones como verdades absolutas e incuestionables, impulsando y reafirmando la ideología que los aborígenes en América devoraban a sus compañeros a partir de la consideración del almirante Cristóbal Colón.

Este pensamiento y enfoque fue apoyado por teólogos y frailes. Es el caso del dominico Tomás Ortiz, quien afirmó en un informe enviado al Consejo de Indias:

Comen carne humana en la tierra firme, son sodométicos más que en generación alguna; ninguna justicia hay entre ellos; andan desnudos, no tienen amor ni vergüenca; son estólidos, alocados no guardan verdad si no es a su provecho; son inconstantes, no saben qué cosa sea consejo; son ingratísimos y amigos de novedades (...) Son bestiales, précianse de ser abominables en vicios; ninguna obediencia ni cortesía tienen mozos a viejos, ni hijos a padres. No son capaces de doctrina de castigo. (...) comen piojos y arañas y gusanos crudos, doquiera que los hayan; no tienen arte ni maña de ser hombres (Todorov, 1987, p. 162).

El teólogo Juan Ginés de Sepúlveda con una visión dualista basada en las ideas de Aristóteles sobre la esclavitud natural de los inferiores, consideraba que los indios eran salvajes por vivir al lado de animales, al no tener un régimen político, por la carencia de un sistema de leyes escritas y debido a sus características físicas más cercanas a los monos que a los hombres. Por el contrario, al europeo lo encuadró con las virtudes de la prudencia, humildad, monógamos, respetuoso, cortés, con ingenio, templanza y creyente de Dios (Estermann, 2014).

Estos argumentos y prácticas antropófagas fueron exagerados por quienes buscaban e incluso se ufanaban en censurar las características culturales y sociales de estas comunidades. Por tanto, hubo un proceso de colonialidad del ser a través de la subalternización, inferiorización y deshumanización: a lo que el investigador Frantz Fanon se refirió como el trato de la no existencia, apuntalando así la relación entre razón-racionalidad y humanidad. Es a partir de esta consideración que se ha pensado construir el Estado nacional, históricamente ubicando a los nativos y negros como incivilizados, no modernos e incluso no existentes (Walsh, 2008).

Circunstancia y elementos que no tuvieron en cuenta intelectuales, políticos y cineastas que promovieron esta visión y, en casos, hasta rechazaron el legado cultural que dejaron y siguen realizando estos grupos étnicos. A la par, guardaron silencio con respecto al canibalismo que practicaron los europeos debido a que en más de una ocasión y bajo la presión del hambre fueron 
tentados a realizar esta práctica que consideraban monstruosa. Incidente, recreado por el productor y, rechazado por el fraile Santiago cuando exclamó: "Que horror es este" (Lamata,1990). Es preciso advertir que en los territorios de la actual República de Venezuela no hubo grandes comunidades aborígenes en época colonial. Esto no implica que no tengamos referencias de estos pueblos debido a los hallazgos arqueológicos, a los testimonios de cronistas y a investigaciones de tipo histórico.

En el ámbito de la historia oficial, el presidente Marcos Pérez Jiménez, estigmatizó así a esta comunidad: “(...) nosotros, dentro de nuestra conformación indígena tenemos tendencia a la pereza. $Y$ podemos alimentarnos sin trabajar, lo que hacemos" (Paz, 2000, p. 70).

El abogado, filósofo y político, Laureano Vallenilla Lanz (citado en Castillo, 2003), afirmó lleno de prejuicios:

Tampoco existe un arte precolombino porque desde el punto de vista estético son insignificantes los cacharros de arcillas y los ídolos que improvisados etnólogos y arqueólogos vernáculos presentan como pruebas de pretéritas civilizaciones. (...) Nosotros no somos antiindigenistas, pero nos felicitamos que en Venezuela no hay indios y nos oponemos al mantenimiento de tradiciones que son fruto de la miseria, de la ignorancia y el atraso (Vallenilla Lanz, citado en Castillo, 2003, p. 10-111).

Estas posturas sirven para explicar las políticas del gobierno de Pérez Jiménez quien pretendía que los aborígenes se incorporaran a la cultura nacional, forzando a estos grupos a renunciar a su cultura, de conformidad con los planteamientos del Nuevo Ideal Nacional, en la que confluyen rasgos provenientes de la concepción positivista de desarrollo social, la cual considera que para lograr el "orden y progreso" en un país se necesita el progreso de los pueblos originarios. Estas premisas, consideran a los nativos como seres incapaces de adecuarse y responder a las exigencias económicas que los lleven a un desarrollo acelerado (Paz, 2000).

Esta "inclusión" de los indígenas, parte de la dominación, actitud asistencialista y patriarcal. Dinámica donde hay un sujeto activo incluyente y otro objeto o grupo social incluido. El trasfondo de este objetivo es un proceso de "bienestar", "desarrollo", "modernidad", "tecnológico", "participativo" y de "consumo capitalista" (Estermann, 2014). El investigador Stuar Hall (2003) considera que las identidades se construyen a través de la diferencia, son el resultado de la exclusión de los hilos del poder, por lo tanto, no son esencialistas, sino estratégicas y posicionales. En este orden de ideas, la élite política venezolana no tuvo la intención de promover el conocimiento de esa diferencia debido a que su proyecto de Estado-nación era unificar y coaccionar a estos grupos en aras de conformar una sociedad culturalmente homogénea (García, 2003). 
Otra posición antiindígena la impulsó Arturo Uslar Pietri. El discurso central giró en torno al mestizaje y la idea de un hombre nuevo americano, su pensamiento más difundido se observa en la afirmación de que Venezuela es un crisol de <<razas >> donde:

Lo que surgió no era, ni podía ser europeo, como tampoco pudo ser indígena o africano. Las tres culturas, en grado variable, se combinaron y mezclaron para crear un hecho diferente todavía no enteramente reconocido ni definido, que se reflejó en todas las formas de vida, de mentalidad y de la relación de las gentes (Rodríguez, 2016, p. 20).

Sobre esta idea de razas se apalancaron los conquistadores del siglo XVI y se clasificó la población de la América española. Esa supuesta diferenciación biológica colocó a unos en inferioridad respecto a otros. Desarrolló un esquema basado en las diferencias fenotípicas que llevó a la articulación de relaciones sociales, económicas, políticas y surgimiento de identidades nuevas: indios, negros, mestizos, blanco, entro otras. Esta teoría de la raza fue un elemento de dominación que permitió la expansión del colonialismo europeo y legitimó las relaciones de superioridad (Quijano, 2014). Como expresó John Winthrop unos habían nacido para gobernar, ser ricos, elevados de poder y otros para obedecer, ser humildes y sumisos (Elliott, 2006). Este símbolo de raza de manera literal es un invento, una construcción que no tiene nada que ver con la estructura biológica de la especie humana debido a que los subsistemas neurológicos y mentales no los determina esa condición. (Quijano, 2014)

En cuanto al cartabón de películas de la década de los 80 con estas líneas de pensamientos tenemos: Caballo salvaje (1981), Orinoko nuevo mundo (1984), Ya koo (1985), Cubagua (1987) y Amérika, terra incógnita (1988). La representación del nativo en estas producciones, de manera general, presentaron una postura maniquea y un parámetro entre lo que es civilizado y bárbaro. Esta distinción abarcó un componente ideológico que ratificó el orden colonial que descansaba en la sociedad dominante en todos los aspectos de comparación con los pueblos originarios.

A partir de un análisis crítico de sus discursos se pueden identificar elementos que permiten distinguir tres tendencias. La primera podría catalogarse de naturalista debido a que resalta la selva, los animales salvajes y al nativo lo codifica como un objeto dentro de ese escenario natural por lo que en este grupo se ubica la película Caballo salvaje. La segunda se relaciona con el cine de conquista militar, en ella se encuentran los filmes Orinoko, nuevo mundo, América, terra incógnita y Cubagua. Las diferencias entre estas películas radicaron en que la primera reveló la colonización y conquista territorial y religiosa de los nativos. El aborigen se inscribió en la noción del buen salvaje. Cubagua, por su parte, continúa con esa interpretación, aunque toma como referencia la novela del mismo nombre, de Enrique Bernardo Núñez. Este filme evidencia como el proceso de despojo y apropiación de la 
tierra por parte de europeos afectó a las comunidades aborígenes. Aunque ninguna de las dos cinematografías se aleja de las posturas oficiales de la historia de Venezuela. La tercera categoría es la de cine de conquista religiosa, la cual en apariencia realiza una crítica a la Iglesia católica durante los primeros años de colonización española. En esta se sitúa la cinta Ya-koo del director Franco Rubertelli, que muestra la conquista religiosa de las sociedades autóctonas venezolanas (Rodríguez, 2016).

Estos largometrajes desconocieron las corrientes de América Latina que se impulsó en los 80 de forma empoderada por el Grupo Latinoamericano de Estudios Subalternos, principalmente a través de sus integrantes, el semiólogo Walter Mignolo a quien se le atribuyó el intento de evidenciar el locus poscolonial de enunciación. Aunque uno de los primeros trabajos donde se maneja un discurso poscolonial surgió en la década de mediados de 1960 con la aparición del artículo El indigenismo en el Perú: la razón de ser del indigenismo del antropólogo José María Arguedas (Sosa, 2009).

También ignoraron al Congreso Indio de Sudamérica (CISA) cuyos representantes eran argentinos, peruanos, colombianos, chilenos, paraguayos, bolivianos, ecuatorianos, brasileros y, por supuesto, venezolanos. Quienes afirmaron en 1983 que ellos eran dueños y protagonistas de su propio destino, propugnaban por la autodeterminación y eran una alternativa a la sociedad occidental que estaba en crisis moral. (Chihuailaf, 2018) Asimismo olvidaron que Venezuela se suscribió al convenio 107 de la Organización Internacional del Trabajo (OTI) cuyo Art. 7 expresaba que los indígenas tenían derecho consuetudinario y por tanto a mantener sus costumbres e instituciones cuando estas no sean discordantes con el ordenamiento jurídico (Arreaza, 2010).

Estas producciones influyeron en la representación colectiva de los ciudadanos y en la opinión pública y en el estereotipo de los grupos étnicos que hacen presencia en el territorio. Fundado en una ideología subjetiva del grupo dominante que busca a través de sus reglas y convenciones acentuar una diferencia para mantener su statu quo. Esto no quiere decir que las mentalidades colectivas sean todas impuestas ya que el individuo y la sociedad tienen la capacidad de rebatir y competencia suficiente para construir su propia interpretación.

Sin embargo, los estereotipos son un mapa mental de las relaciones humanas que condicionan el comportamiento de las personas debido a que estimulan una percepción inconsciente, un imaginario en la memoria social que media entre los derechos y deberes de los individuos y privilegios de otros. Dicho de otro modo, la consolidación de los estereotipos conlleva a regular el nivel de visibilidad como la legitimidad de los distintos individuos que conforman la sociedad (Persánch, 2018). 
Estas representaciones son un conjunto de creencias codificadas y no simples etiquetas mentales que orientan la conducta debido a que tienen alcances profundos entre el individuo y su contexto. Tienen cuatro funciones: cognitiva, orientativa de la acción, justificativa y de identidad. (García, 2008) Es por tanto que el concepto de identidad cultural es polisémico, el cual es construido de diferentes y múltiples formas a través de prácticas, discursos y posiciones a menudo antagónicas. La teoría de la diferencia es la más aceptada en el campo teórico contemporáneo la cual impulsa una noción fuerte de esa diferencia. La otredad, por el contrario, reconoce la existencia del otro en un mismo espacio, a partir de la divergencia (Grossberg, 2003).

Es decir, la alteridad u otredad es un grupo de seres humanos o elementos culturales que no me pertenecen a mí. Cuando se utiliza esta categoría en el descubrimiento de América se hace para referirse a unos hombres con manifestaciones disímiles, de un lado la visión europea, y del otro los aborígenes americanos (Buganza, 2006). En otras palabras, la identidad cultural se construye a través de procesos dinámicos de carácter históricos en el que confluyen pugnas, roces, luchas, confrontaciones, negaciones, concesiones, en el ámbito social, simbólico, individual, emocional y mental (García, 2003).

Estos conceptos teóricos, afirmaciones y representaciones nos permiten develar que aún en la década de los 80, persistía en el imaginario colectivo un perfil negativo de los nativos. Estas ideas guardan una estrecha relación con la construcción de las imágenes, y por ende con el cine histórico de ficción. Con respecto a la intencionalidad del largometraje Jericó, es una reflexión que pretendió dar otra mirada y representación al indígena, alejándose del eurocentrismo de academicistas y cineastas venezolanos. Como se sustentó, consideraban al indio como bárbaro y atrasado; como seres inferiores, incapaces de enfrentar y responder a las exigencias del siglo XX.

Destacamos como la sexualidad y la desnudez del indio fueron consideradas de manera "extraordinaria", o más bien pecaminosas, con descalificativos moralistas (sodomitas, bestias, incapaces de sentir amor, sin vergüenza), para impulsar que el europeo era superior y legitimar el proceso de conquista y vasallaje. De ahí el distanciamiento en la simbolización del historiador y cineasta Lamata debido a que no mostró la desnudez y la sexualidad de manera libidinosa, por el contrario, como parte de las características culturales de estos grupos étnicos y quizás más importante aún, reveló que sentían amor hacia el otro, en otras palabras, amaban y, al igual que los europeos, la mayoría de sus relaciones sexuales se basaban en sentimientos mutuos.

La simbolización femenina es importante en Jericó, la hermana del fraile Santiago recuerda la partida de su familiar hacia América. La mujer indígena no es presentada como colaboradora para que europeos se internen en el 
territorio americano y destruyan a la comunidad nativa. Por el contrario, se apartó de producciones comerciales que ratificaban el mito de La Malinche (Arreaza, 2010).

La película muestra que tenían fuertes vínculos familiares, que participaban en juegos y compartían actividades en los diferentes espacios de sociabilidad, fortaleciendo los lazos de amistad e identificación cultural. Incluso nos permitió distinguir cómo el sistema de símbolos en la piel era importante no solo como identidad, reconocimiento y diferenciación, sino para sus ritos fúnebres, para así dejarnos ver entre líneas que las ceremonias significaban la existencia de una creencia religiosa. Nos develó que los indios no profesaban las normas eclesiásticas con respecto al matrimonio, bautismo, entierros y comunión. A la par, nos mostró collares, lanzas y artefactos musicales como tambores, maracas que se utilizaban para amenizar las danzas y fortalecimiento social. Instrumentos musicales que en la actualidad son empleados por las gaitas zulianas, género musical declarado Patrimonio Cultural de Venezuela.

Otros elementos que permitieron al director alejarse de posturas cinematográficas preliminares, es que estas no eran comunidades cerradas, o mejor dicho, que tenían la capacidad de realizar intercambios comerciales en su área de influencia. A pesar de que esa misma cercanía los llevara a tener roces y desencuentros con otros grupos. El filme insiste en exhibir a un indio en su vida cotidiana, como recolector, evidencia las características principales de su vivienda tanto en la infraestructura externa como la organización espacial interna, las actividades de subsistencia y pautas sociales de su comportamiento diario que les permitía convivir de acuerdo con sus propias reglas y necesidades.

Esto no quiere decir que no se presentaran desavenencias entre las comunidades nativas, como el rechazo y expulsión sufrida por la familia del fraile. Escena que permitió al director develar que no vivían en ningún paraíso antes del arribo de los europeos y por tanto no eran inocentes e ingenuos como lo promocionó Diego Risquez y Michel New en sus películas; y atestiguó Bartolomé de la Casas:

(...) entre todas las razas, crio Dios los más simples, sin maldades ni dobleces, obedientísimas, fidelísimas a sus señores naturales y a los cristianos a quien sirven; más humildes, más pacientes, más pacíficas y quietas, sin rencillas ni bullicios, no rijosos, no querulosos, sin rencores, sin odios, sin desear venganzas, que hay en el mundo (De las Casas, 2011, p. 13).

En otras palabras, no los imaginemos pasivos, fascinados con los objetos provenientes de Europa, víctimas embrutecidas de la rapacidad y de los perros de los conquistadores, sino aborígenes que sabían revertir la relación de la fuerza cuando encontraban los medios para hacerlo, defender sus tierras, 
liquidar a sus agresores, acosar al invasor y rechazar la religión (Gruzinski y Bernad, 1996).

Asimismo, mostró estrategias de cacería y enfrentamientos por el territorio, disputa que acarreó la muerte de un nativo. Deslegitimó las posturas ideológicas, pretendidas como científicas, y rechazó el silencio del idioma aborigen debido a que ningún filme de la década de los 80 lo había tenido en cuenta. Un ejemplo es cuando el religioso le intenta enseñar a un indio el término fuego y este responde "naimi" (Lamata, 1990) develando que tienen inteligencia y capacidad de entendimiento, que incluso los llevó a componer canciones. No menos importante, es que logró evidenciar a través de Santiago el sincretismo existente entre Europa y América. Este aprendió a dormir en hamaca, consumir tabaco, sustancias alucinógenas y oraciones de la lengua nativa.

Jericó no solo exhibió que hubo un proceso de conquista territorial, militar, religiosa y de colonización, sino también un mestizaje cultural que políticos, "intelectuales" y cineastas intentaron ocultar por tener una especie de complejo de inferioridad. Además, confrontó las posturas evolucionistas que considera que las sociedades primitivas pasan de allí a la barbarie y después al estado de civilización debido a que la sociedad se desarrolla a través de su propio ritmo histórico.

Dos años después del estreno de Jericó se inició la celebración de los quinientos años del encuentro, desencuentro, resistencia, invasión y choque del quizás hecho histórico más importante, el descubrimiento de América. La festividad partió desde la oficialidad mediante el Decreto 174 del 17 junio de 1984 con la creación de la Comisión Nacional para la Conmemoración del Quinto Centenario del Descubrimiento de América. Encuentros de dos mundos. La cual era presidida por el Ministerio de Relaciones Exteriores e integrada por los Ministros de Educación, Defensa, Información y Turismo, Secretaria de la Presidencia de Estado para la Cultura y por el presidente de la Academia Nacional de Historia (Ministerio de Relaciones Exteriores, 1992).

El decreto fue modificado en agosto de esa anualidad para establecer de manera precisa las funciones de la comisión, las cuales abarcaron de manera sucinta la sucesiva programación: rescate, restauración y rehabilitación de sitios y monumentos de valor histórico y arquitectónico. Además, preservación y difusión del acervo impreso referido al origen de la sociedad americana, de los fondos documentales históricos, públicos y eclesiásticos (Ministerio de Relaciones Exteriores, 1992).

A medida que se aproximaba el 12 de octubre de 1992 y del éxito del largometraje se desarrollaron diversas actividades, en teatros, parques, universidades, bibliotecas, notas periodísticas, marchas en las calles, a favor 
y en contra de la conmemoración. En tal sentido, Carlos Orta desde una perspectiva urbana realizó una coreografía que fue puesta en escena por la compañía dancística, Coreoarte, en la Sala Anna Julia Rojas del Ateneo de Caracas, que abordó el tema del encuentro cultural que dio origen al hombre americano (Últimas Noticias, 1992).

Por otro lado, se escuchó la opinión del padre Juan Vives Suriá, presidente de Fundación Latinoamericana por la Paz y los Derechos Humanos (FUNDALATIN), momentos antes de partir hacia Santo Domingo para promover la campaña denominada <<América 501. Dignidad y Soberanía > : "Nuestra América hoy padece los males de la deuda, el cólera, empobrecimiento, corrupción, dependencias, fatiga democrática, pero emerge con mayores reservas que nunca, para construir el futuro". (Últimas Noticia, 1992, p. 6) Según, Octavio Paz, mexicano ganador del Premio Nobel de literatura: "Renegar de las tradiciones europeas, en nombre de un indigenismo actual, es absurdo y equivale a renegar en español, de los españoles" (Últimas Noticias, 1992, p. 56).

Disímil eran las posturas del Consejo Nacional Indio de Venezuela, y del Departamento de Asuntos Indígenas, de la gobernación del Estado de Bolívar, que rechazaban la celebración ya que debería ser un día de duelo. Por ello propusieron la elaboración de un balance crítico alternativo al Centenario, de acuerdo con los principios de la V Asamblea General del Consejo Mundial de Pueblos Indígenas, realizada en Lima, en 1986. Asimismo, impulsaron tres marchas, las cuales se desarrollarían los días 11 y 12 de octubre. La primera, en La Guaira, y las otras dos, en Puerto Ayacucho y El Tigre (Últimas Noticias, 1992).

Este movimiento indigenista era variopinto y también se apoyaba en la Filosofía intercultural que trataba de colocar en el debate latinoamericano la cultura ancestral nativa, aspecto que criticaba de manera fuerte el etnocentrismo y universalismo por lo que se aproximó a la filosofía clásica de la liberación. Otras corrientes dentro de este movimiento se inclinaron por planteamientos posmodernos como la divergencia y la pluriculturalidad. Además, hubo una tendencia que buscó confluir entre el liberacionismo y la descolonización que sugirió una interculturalidad emancipadora y crítica (Estermann, 2014). Las reivindicaciones sociales y demandas de estos pueblos tuvieron un alcance universal: el cumplimiento efectivo de los derechos humanos, cuidado del medio ambiente, reflexiones sobre conceptos de ciudadanía y autonomía, el cambio climático, el anhelo de consolidar estados pluriétnicos, la aplicación de políticas de desarrollo sustentables y rechazo a procesos globalizadores. (Rodríguez, 2008) Estas organizaciones y movimientos aumentaron en los acercamientos del Quinto Centenario de América y continuaron en la década de los 90 logrando un grado de visibilización y reconocimiento. A la par hubo levantamientos en Ecuador, rebeliones en México y marchas en Bolivia lo cual dio la sensación de un 
despertar de estas comunidades luego de un "silencio" prolongado (Chihuailaf, 2018).

Finalmente, la conmemoración gubernamental oficial en Venezuela se realizó en el Paseo Colón. Estuvo amenizada por bandas, y presidida por el gobernador del Distrito Capital, Antonio Ledezma, junto con el Cónsul de España, en Venezuela, Eduardo de Quezada y representantes de Italia, quienes colocaron una ofrenda floral en la estatua del genovés. Quezada comentó: "que deberían concertarse en los aspectos positivos, y así olvidar las viejas polémicas que no resuelven nada y no llevan a ningún sitio” (El Nacional, 1992).

Estas posiciones opuestas desconocen que la historia de las civilizaciones es la historia de los encuentros. Si alguna población hubiera podido permanecer aislada y encerrada en sí misma, hubiera quedado en una suerte de prehistoria congelada. Fueron los acercamientos de pueblos diferentes por los más variados motivos los que han propiciado los cambios, los nuevos mestizajes, los dificultosos acomodamientos, los avances creadores, de los cuales ha surgido el proceso histórico de las civilizaciones (Uslar, 1998).

\section{Conclusiones}

El recelo existente entre cine y la historia se ha venido superando. La muestra más evidente, es la incursión y dirección del historiador Luis Alberto Lamata en el film Jericó, película estrenada en 1990 en Mérida durante el segundo gobierno de Carlos Andrés Pérez. Fue la interpretación maniquea de cronistas y sesgada de teólogos como Tomás Ortiz y Juan Ginés de Sepúlveda donde se apoyó la oficialidad política, intelectual y el cine venezolano de la década de los 80 para rechazar, invisibilizar y estigmatizar cualquier rastro de estos grupos étnicos. Incluso reafirmaron el concepto de raza con el fin de legitimar una supuesta superioridad biológica. Desconocieron los movimientos y organizaciones como el Grupo Latinoamericano de Estudios Subalternos y el Congreso Indio de Sudamérica que buscaban reivindicaciones sociales por medio de la diferencia y autonomía.

Por el contrario, Lamata se unió a la corriente indigenista y a la Nueva Historia para rechazar los valores culturales universales, hegemónicos y con pretensiones globalizadoras. Ese apoyo al movimiento filosófico intercultural e interpretación histórica le permitió a su película Jericó romper con un paradigma cinematográfico venezolano debido a que desmintió la teoría del buen salvaje de los largometrajes que la antecedieron como Cubagua, América, terra incógnita y Orinoko, nuevo mundo. Expuso como los europeos practicaron el canibalismo en la penetración del territorio de América contradiciendo así sus creencias religiosas. Rechazó las representaciones de los aborígenes de cineastas de los 80 que ratificaban el orden colonial y las aseveraciones de Laureano Vallenilla Lanz y Arturo 
Uslar Pietri quienes promovieron que el atraso material de los nativos se debía a sus tradiciones y a la raza respectivamente. En otras palabras, confrontó las posturas evolucionistas y resaltó que las sociedades se desarrollan por medio de su propia identidad cultural y ritmo histórico.

Asimismo, Jericó tuvo en cuenta la lengua indígena a través de su idioma, hecho que difiere con las otras películas ya que no utilizaron este recurso del cine, ni tampoco la traducción de los propios personajes o subtítulos. Reveló actividades recreativas, ritos fúnebres y símbolos en el cuerpo que le permitía al nativo un mayor fortalecimiento de su identidad cultural. Marcó una separación en la reinterpretación y construcción de la imagen del indio debido a que lo mostró como un ser humano: con creencias, lleno de miedos, que se mueve por intereses; y que tales intereses los llevan a tener conflictos, como artesano, comerciante y padre de familia; comportamientos que le permiten vivir con sus propios patrones sociales y por ende en sociedad. Finalmente, a pesar de los reconocimientos nacionales e internacionales el largometraje no logró apaciguar posiciones antagónicas, controversiales y radicales que se presentaron en la Celebración del Quinto Centenario de América en Venezuela.

\section{Referencias bibliográficas}

Acosta, J. y Suerio, Y. (2000). "Una historia de película: (des) encuentros entre el cine y la historia vistos desde Venezuela”. En J. Á. Rodríguez. (Ed.), Visiones del Oficio Historiadores venezolanos en el siglo XXI (289 -316). Caracas: Fondo Editorial Humanidades.

Arreaza Camero, E. (2010). "Representación del indígena en el cine venezolano de ficción”. Fermentum, 20 (57), 130- 150.

Ayala, E. (1992). Historia, compromiso y política. Quito: Editorial Planeta.

Beresford, B. (1991). El Manto Negro. [Cinta cinematográfica]. Canadá: Telefilm Canadá.

https://www.youtube.com/watch?v=GygwN0MFPCo\&list=PLEH6O6oHI1Vfl6 eZffrqQ2WHRpZ0VjbnE\&index $=37$

Bergeron, E. y Paul, D. (2000). Hacia la ruta del Dorado. [Cinta cinematográfica]. Estados Unidos: DreamWorks Animation/Stardust Pictures.

Buganza, J. (2006). "La otredad o alteridad en el Descubrimiento de América y la vigencia de la utopía lascasiana". Razón y Palabra, (54), S/N.

Burker, P. (2005). Lo visto y no visto. El uso de la imagen como documento histórico. Barcelona: Crítica.

Carrasco, S. (1998). La otra conquista. [Cinta cinematográfica]. México: Carrasco y Domingo Films. https://www.youtube.com/watch?v=86mlx2nOPl8 
Castillo, O. (2003). Los años del buldozer. Ideología y política, 1948-1958. Caracas: Fondo Editorial Tropykos.

Chihuailaf, Arauco. (2018). "Los indígenas en el escenario político de finales del siglo XX", Amérique Latine Histoire et Mémoire. Les Cahiers ALHIM, 36, S/N.

Cortés, J. (1981). Caballo salvaje. [Cinta cinematográfica]. Venezuela: Sin identificar.

De Las Casas, B. (2011). Brevísima relación de la destrucción de las indias. Medellín: Editorial Universidad Antioquia.

Echevarría, N. (1990). Cabeza de Vaca. [Cinta cinematográfica]. México: Instituto Mexicano de Cinematografía/ Televisión Española.

Elliott, J. (2006). Imperios del mundo Atlántico. España y Gran Bretaña en América. Madrid: Tauros.

El Nacional. (12 de octubre, 1992). "Entre descubiertos y no descubiertos", Caracas, pág. S/N (Sección C).

Estermann, J. (2014). “Colonialidad, descolonización e interculturalidad". Polis. Revista Latinoamericana, (38), 1-18.

García Martínez, A. (2008). "Identidades y representaciones sociales: La construcción de las minorías". Nómadas 18 (2), 211-222.

García Gavidia, N. (2003). "El uso de símbolos indígenas en la invención de la identidad nacional". Opción, 19 (40), 9-34.

Glen, J. (1992). Cristóbal Colón. El descubrimiento. [Cinta cinematográfica]. Estados Unidos: Chrisstopher Columbus Productions.

Grossberg, L. (2003). "Identidad y estudios culturales: ¿No hay nada más que eso?”. En S. Hall y P. Gay. (Comps), Cuestiones de Identidad Cultural. Buenos Aires: Amorrortu.

Gruzinski, S. y Bernad, C. (1996). Historia del Nuevo Mundo. Del descubrimiento a la conquista. La experiencia europea.1492-1550. México: Fondo de Cultura Económica.

Guerra Vilaboy, S. (2003). "Las grandes corrientes de la historiografía latinoamericana". Revista Clío, 71 (166), 145-182.

Hall, S. (2003). “Introducción: ¿Quién necesita «identidad?”. En S. Hall y P. Gay. (Comps), Cuestiones de identidad cultural. Buenos Aires: Amorrortu.

Lamata, L. (1990). Jericó. [Cinta cinematográfica]. Venezuela: Thalía producciones/ Foncine. https://www.youtube.com/watch?v=Mz16XH8SC0A 
Lamata, L. (1985-1986). Cristal. [Telenovela]. Venezuela: Coraven/Radio Caracas Televisión.

Lamata, L. (1985). Topacio. [Telenovela]. Venezuela: Coraven/ Radio Caracas Televisión.

Lamata, L. (1991-1992). La traidora. [Telenovela]. Venezuela: Marte Televisión.

Martínez, F. (2013). “La historia y el cine: ¿Unas amistades peligrosas?”. Vínculos de Historia, (2), 351-372.

Ministerio de Relaciones Exteriores. (1992). Comisión Nacional para la Conmemoración del Quinto Centenario del Descubrimiento de América. Encuentros de dos mundos.

Montero, J. (2008). "La «realidad» histórica en el cine. El peso del presente”. En B. De las Heras y V. de Cruz. (Ed.), Una ventana indiscreta. La historia desde el cine (163-176). S/C: Ediciones JC.

New, M. (1987). Cubagua. [Cinta cinematográfica]. Venezuela: Sin identificar.

Ocampo, J. (2009). "La microhistoria en la historiografía general". Historelo. Revista de Historia Regional y Local, 1 (1), 202-228.

Quijano, A. (2014). “Colonialidad del poder, eurocentrismo y América Latina”. En D. Assis Clímaco. (Comp.), Cuestiones y horizontes: de la dependencia históricoestructural a la colonialidad/descolonialidad del poder (777- 832). Buenos Aires: CLACSO.

Paz, C. (2000). "Las políticas indigenistas en el marco del nuevo ideal nacional". Espacio Abierto, 9 (3), 365-390.

Persánch, JM. (2018). "Laberinto de espejos: estereotipos latinos, blanquitud y memoria colectiva estadounidense a través del Mariachi, 1992". Procesos Históricos, (34), 17-31.

Ríquez, D. (1984). Orinoko nuevo mundo. [Cinta cinematográfica]. Venezuela: Guakamaya.

https://www.youtube.com/watch?v=OISFqwbHn0I\&has verified=1

Ríquez, D. (1988). América, terra incógnita. [Cinta cinematográfica]. Venezuela: Guakamaya.

Rodríguez, F. (2016). “Cine, poder e historia: la representación y construcción social del indígena en el cine de ficción venezolano durante la década de los 80 ". Campos, 4 (1), 11-31.

Rodríguez Mir, J. (2008). "Los movimientos indígenas en América Latina. Resistencias y alteridades en un mundo globalizado". Gaceta de Antropología, 2 (24), 1-15. 
Rosentstone, R. (2008). "Inventando la verdad histórica en la gran pantalla". En B. De las Heras y V. de Cruz. (Ed.), Una ventana indiscreta. La historia desde el cine (9-18). S/C: Ediciones JC.

Rubertelli, F. (1985). Ya Koo. [Cinta cinematográfica]. Venezuela: Sin identificar.

Sánchez Norie, J. (2008). “De la «película histórica» al cine de la memoria”. En B. De las Heras y V. de Cruz. (Ed.), Una ventana indiscreta. La historia desde el cine (87-96). S/C: Ediciones JC.

Saura, C. (1988). El Dorado. [Cinta cinematográfica]. España: Lolafilms/Iberoamérica TV.

Sorlin, P. (2008). "Cine e historia. Una relación que hay que repensar". En B. De las Heras y V. de Cruz. (Ed.), Una ventana indiscreta. La historia desde el cine (19-32). S/C: Ediciones JC.

Sosa, E. (2009). "La otredad: una visión del pensamiento latinoamericano contemporáneo". Letras, 51, (80), 349- 371.

Scott, R. (1992). 1492. La conquista del paraíso. [Cinta cinematográfica]. Reino Unido: De Lane Studios Center London/Pinewood Studios/Panavisión. https://www.youtube.com/watch?v=qgF4k2cXsjg

Todorov, T. (1987). La conquista de América, el problema del otro. México: Siglo XXI Editores.

Últimas Noticias. (30 de septiembre de 1992) "Organizaciones indígenas rechazan celebración del V centenario”. Caracas, pág. 28.

Últimas Noticias. (8 de octubre de 1992) "Los recién llegados" por los 500 años. 1992”. Caracas, pág. 56.

Últimas Noticias. (12 de octubre, SA) "Los 500 años encuentran a la Iglesia muy preocupada por la "Leyenda Negra”. Caracas, pág. 51.

Últimas Noticias. (12 de octubre de 1992) "Nuestra América llega a 500 años con un grave retroceso histórico”. Caracas, pág. 6.

Uslar Pietri, A. (1998). “El mestizaje y el Nuevo Mundo”. En C. Rey de Guido. (Comp.), Nuevo mundo, mundo nuevo (63-72). Caracas: Biblioteca Ayacucho/Fundación Cultural Chacao.

Walsh, C. (2008). "Interculturalidad, plurinacionalidad y decolonialidad: las insurgencias político-epistémicas de refundar el Estado". Tabula Rasa, (9), 131152. 